\title{
Chapter 4 \\ Operation and Maintenance Costs of Offshore Wind Farms and Potential Multi-use Platforms in the Dutch North Sea
}

\author{
Christine Röckmann, Sander Lagerveld and John Stavenuiter
}

\begin{abstract}
Aquaculture within offshore wind farms has been identified as one of the many possibilities of smart use of marine space, leading to opportunities for innovative entrepreneurship. Offshore areas potentially pose less conflict with co-users than onshore. At the same time, offshore areas and offshore constructions are prone to high technical risks through mechanical force, corrosion, and biofouling. The expected lifetime of an offshore structure is to a great extent determined by the risk of failures. This chapter elaborates on logistical challenges that the offshore industry faces. Operation and maintenance (O\&M) activities typically represent a big part of the total costs (e.g. 25-30\% of the total lifecycle costs for offshore wind farms). The offshore wind energy sector is considered an industry with promising features for the public and private sector. Large wind farms farther off the coast pose high expectations because of higher average wind speeds and hence greater wind energy yield (in terms of megawatts per capital). These conditions entail additional challenges in logistics, though. One of the main hurdles that hinders use of offshore wind energy is the high cost for O\&M. The offshore wind industry will have to solve these problems in order to achieve substantial cost reduction - alone or jointly with other (potential) users. It is precisely the logistical problems around O\&M where most likely synergy benefits of multi-use platforms (MUPs) can be achieved. The offshore wind energy industry is eagerly looking for technical innovations. Until now they mostly sought the solutions in their own circles. If the combination of offshore wind energy and offshore aquaculture proves to be feasible and profitable in practice, there may be an additional possibility to reduce the O\&M costs by synergy effects of the combined operations. Logistic waiting times, for example, can result in substantial revenue losses, whereas timely spare-parts supply or sufficient repair capacity (technicians) to shorten the logistic delay times are beneficial. A recent study suggests that a cost reduction of $10 \%$ is
\end{abstract}

C. Röckmann $(\bowtie) \cdot$ S. Lagerveld

Wageningen University and Research-Wageningen Marine Research,

P.O. Box 57, 1780 AB Den Helder, The Netherlands

e-mail: Christine.rockmann@wur.nl

J. Stavenuiter

Asset Management Control Centre, Willemsoord 29, 1781 AS Den Helder, The Netherlands

(C) The Author(s) 2017

B.H. Buck and R. Langan (eds.), Aquaculture Perspective of Multi-Use Sites

in the Open Ocean, DOI 10.1007/978-3-319-51159-7_4 
feasible, if the offshore wind and offshore aquaculture sectors are combined in order to coordinate and share O\&M together. The presented asset management control model proves useful in testing the innovative, interdisciplinary multi-use concepts, simulating return rates under different assumptions, thus making the approach more concrete and robust.

\subsection{Introduction}

Aquaculture within offshore wind farms has been identified as one of the many possibilities of smart use of marine space, leading to opportunities for innovative entrepreneurship (Buck 2002; Buck and Krause 2012; Michler-Cieluch et al. 2009a, b; Michler-Cieluch and Krause 2008; Lagerveld et al. 2014; Verhaeghe et al. 2011). Offshore areas potentially pose less conflict with co-users than onshore. Large wind farms farther offshore are considered promising because of higher average wind speeds and hence greater and more constant wind energy yield in terms of megawatts per capital. Similarly, positive assets to aquaculture offshore are the often favorable conditions for growth due to water depth and hydrodynamics (e.g. quick nutrient input and waste dispersal), and less potential for disease spread, pollution and agricultural interactions. At the same time, offshore areas and offshore constructions are prone to high technical risks and entail additional logistical challenges.

This chapter elaborates on logistical challenges concerning operation and maintenance $(\mathrm{O} \& \mathrm{M})$ of offshore activities. O\&M activities typically represent a big part of the total costs, which are some of the main hurdles that hinder use of offshore wind energy. It is precisely the logistical problems around O\&M where synergy benefits of multi-use platforms (MUPs) can most likely be achieved. The offshore wind energy industry is eagerly looking for technical innovations and until now, they mostly sought the solutions in their own circles. If the combination of offshore wind energy and offshore aquaculture proves to be feasible and profitable in practice, there may be additional possibilities to reduce the O\&M costs by synergistic effects of the combined operations. Reducing logistic waiting times, for example, can result in substantial cost savings, just as timely spare-parts supply or sufficient repair capacity (technicians) are beneficial to shorten the logistic delay times. If the offshore wind and aquaculture sectors join forces, O\&M activities can be coordinated and shared together and thus costs saved. The aquaculture sectorin order to be recognized as a potential partner-still has to demonstrate its feasibility offshore, though, under the wide range of rough oceanographic conditions. Aquaculture at offshore sites faces major challenges compared to coastal and land based production systems. The longer transport distances result in higher O\&M costs than for coastal sites. Although technical solutions have been developed and are available (e.g. Gimpel et al. 2015; Buck et al. 2010), offshore aquaculture in the North Sea is still absent due to economic/financial reasons and a lack of cross-sector 
planning. A combination of an offshore wind farm with aquaculture, e.g. as proposed already in 2002 by Buck (2002), Buck et al. (2004) and recently for the Dutch North Sea by Lagerveld et al. (2014), involves both risks and benefits. The potential risks include technical failures due to corrosion and biofouling; ecological risks, such as underwater-noise disturbance of marine mammals, disturbance of the seabed sediments and seabed communities; collision risks to birds and bats above water, and attraction of invasive species. Benefits of combining an offshore wind farm with offshore aquaculture can be found in eco-facilitation and in economic/financial savings. Eco-facilitation refers to the enhancement of biological diversity and production (e.g. by offering increased food availability and shelter, thereby attracting flora and fauna). The economic/financial benefit refers to expected synergy effects through sharing and thus savings on operation and maintenance costs (Krause et al. 2011).

Section 4.2 provides an overview of relevant offshore O\&M activities and an analysis of O\&M costs. Section 4.3 describes the potential for cost savings in a combined offshore Multi-Use Platform (MUP), based on the example of a virtual offshore wind-mussel-farm (OWMF), and it also depicts an Asset Management Control (AMC) model, that could help to manage such a combined business. The AMC model can, for example, simulate different O\&M scenarios of a virtual OWMF over 20 years. The chapter concludes with lessons learned and recommendations for pilot studies.

\subsection{Offshore Operation and Maintenance Activities}

\subsubsection{Accessibility of Offshore Wind Farms}

The offshore marine environment is characterized by harsh conditions. Project developers of offshore wind farms have to cope with many logistical and safety issues that developers of wind energy projects on land do not, or at least not to the same extent. Operation and maintenance costs make up 25-30\% of the total costs of an offshore wind farm (Miedema 2012, cf. Sect. 4.2.5). This is almost as much as the cost of the wind turbines and about as much as the costs of construction and installation. Individual offshore wind turbines currently require about five site visits per year: one regular annual maintenance visit, and three to four visits in case of malfunction (cf. Noordzeewind website). With technological progress, this can potentially be reduced to three visits per year. Nonetheless, a future offshore wind farm consisting of 200 turbines of $5 \mathrm{MW}$ each will therefore need some 3000 offshore visits per year. Operation and maintenance (O\&M) visits are carried out by boat or helicopter, which means that the personnel performing the repair, has to climb onto the turbines. Especially in rough conditions-helicopters for example are used at wind speeds of up to $20 \mathrm{~m} / \mathrm{s}$ - this is a risky undertaking. Systems need to be developed to ensure the safety of staff and to expand workability. 
In the future, certain maintenance tasks may also be carried out remotely (see DOWES, Sect. 4.2.4).

Until now, O\&M visits are carried out when the significant wave heights (SWH) are less than or equal to $1.5 \mathrm{~m}$. According to Stavenuiter (2009), each support vessel has a certain maximum allowable significant wave height for several operations. Therefore, the availability of a vessel is correlated with the occurrence of certain significant wave heights. The cumulative occurrence of significant wave heights less than or equal to $1.5 \mathrm{~m}$ is $68 \%$. Waves up to $2.0 \mathrm{~m}$ increases the cumulative occurrence to $83 \%$ (Stavenuiter 2009). Significant wave heights measured close to two Dutch offshore wind farm locations (OWEZ and PAWP) are almost identical, despite a distance of $40 \mathrm{NM}$ between each other (Rijkswaterstaat 2009).

The number of days per month that offshore locations are accessible or not due to weather downtime varies over the year, with more no access days during the windy and stormy winter months (Stavenuiter 2009). The maximum number (22) of no access days of two offshore locations, very close to the Dutch offshore wind farms OWEZ and PAWP, in 2009 was in November. In spring and summer months, weather downtime fluctuated between 6 and 11 days between April and August 2009, and 16 in September 2009 (Stavenuiter 2009).

The possibility of larger wave heights will require new systems for safe O\&M personnel transfer. If transfers are to be restricted to wave heights of $1.5 \mathrm{~m}$, this will limit offshore work to about 200 days a year (Noordzeewind 2010; Miedema 2012). Noordzeewind (2010) estimated a total of approximately 218 possible access days in 2009, and the remaining time of the year was considered non-productive time ('weather downtime') in 2009. According to a study in the German North Sea, available working days were estimated to be even lower, in a range of 30100 days/year (Michler-Cieluch et al. 2009a). Increasing the workable significant wave height from 1.5 to $2 \mathrm{~m}$, could increase the accessibility of wind farms by $15 \%$ (Stavenuiter 2009). An increase of the safe working wave height to $3 \mathrm{~m}$ and above could increase the number of days available for transfers up to 310 days per year. Hence, increasing overall accessibility can lead to cost reduction of wind energy production. To achieve this, new ships with motion stabilizers are required to guaranty safe transfers of personnel and material. Current solutions are offshore access systems such as 'Ampelmann', a hydraulic ship-based transfer platform that compensates the vessel's motions, thereby enabling safe offshore access and operations. But even if these new systems for operating in far-offshore conditions are developed, a constant shuttling of workboats to and from the coast is impractical and costly. Therefore, developers and offshore service providers are looking for new methods, one of which is the 'mother ship' approach. A single large vessel would then service one or more offshore wind farms staying in the neighborhood of these farms for long periods of time and deploying multiple smaller craft for daily servicing. 


\subsubsection{Infrastructure for Cabling and Cable Repair}

Up to now, there are neither standardized practices nor procedures to procure cables or share cabling equipment, ships, and all other elements necessary for a safe and speedy repair. If developers were more willing to collaborate with each other, to share facilities, vessels, and their particular knowledge, this could lead to far more efficient procedures through economies of knowledge. So far, the desire to keep cable choices and technologies confidential prevailed over the opportunity to develop a more efficient infrastructure for joint installation and maintenance or repair of cables. But these facilities will be necessary as bases for long-range offshore vessels and to service the offshore wind farms closer to the shore. Especially with future far and large offshore wind farms (FLOW), it could be a unique asset to have manufacture and dedicated repair and storage facilities for spare parts closer to the FLOW sites. Despite the benefits to be expected, it is far from certain whether developers and offshore operators are willing to pay for collective facilities that they may not need to use.

\subsubsection{Trained Staff}

To keep up with developments, companies will need to permanently invest in capacity building and training to ensure that sufficiently skilled O\&M personnel are available. This holds even more for FLOW farms. A rough calculation suggests that one O\&M job will be created for every two turbines installed. With 200 turbines of $5 \mathrm{MW}$ each, this equates to a need of about 100 FTE of trained staff. Even if this calculation is conservative, and the number of staff can be reduced through greater efficiency, there will still be a huge need for skilled personnel. To meet that demand, operators and developers will have to set up offshore training centers and training programs. It would not be wise, if they do this just for their own purposes. As with the cabling sector, it is obvious that collaboration and joint financing have great advantages.

\subsubsection{Dutch Offshore Wind Energy Services (DOWES)}

There are three lines of intervention in a wind farm: first, scanner control with remote management; second, helicopter intervention; and third, heavy lift operations. Reactive maintenance, e.g. arranging a site visit if a turbine stops working, is always expensive and can sometimes be impossible; for instance, in bad weather conditions or if boats and crew are unavailable. This dependence on weather, crew, and boat availability increases the risk of an expensive wind generation asset being unable to produce electricity for weeks or even months. Predictive maintenance, 
i.e. remote surveillance, can help in constant monitoring and real time information about what is happening at a site. Key to such planned predictive maintenance is the increased deployment of sensors in offshore wind turbines. Modern offshore wind turbines, particularly those that are custom built for offshore, will contain a huge number $(>1000)$ of sensors in key components. The ongoing Dutch Offshore Wind Energy Services (DOWES.nl) project focuses on developing an innovative information and communications technology (ICT) system to manage offshore wind parks in the Den Helder region (2008-2014). The DOWES management plan aims to lead to high wind farm availability at minimum cost. The ICT system will be capable of reading the sensors on the wind turbines using remote control, making use of the most up-to-date science.

It is possible to manage and maintain offshore wind parks in various ways. DOWES aims to safeguard offshore wind parks from a distance/on land. Constant monitoring of the state of the wind turbines can facilitate timely information of the right people. This can aid in making cost-effective choices and carrying out maintenance optimally. In the long run such systems are expected to increase the manageability of offshore wind parks and reduce maintenance costs.

\subsubsection{Analysis of Operation and Maintenance Costs}

To get more insight in the O\&M cost structure of OWFs, the total O\&M costs are split over specific O\&M disciplines. It starts with the breakdown of the operational expenditures (OPEX) (Fig. 4.1).

This breakdown shows that the O\&M costs represent $53 \%$ of the OPEX (15\% "Operation" $+38 \%$ "Maintenance"). In the Asset Management Control (AMC) approach (Stavenuiter 2002) the discipline "Maintenance" is considered to be the combination of all technical, logistic, administrative and managerial actions during the life cycle of an asset/object, intended to retain the asset or restore it to a state, in which it can perform the required function. Therefore, the activity "Port Activities" is considered a part of "Maintenance". For the UK's seabed, the Crown Estate applies license fees. However, this aspect is not applicable for the offshore wind industry in the Netherlands. For this reason the cost for license fees is also included under "Maintenance". "Other cost" which are not specified by Board (2010; Fig. 4.3) are distributed among the O\&M disciplines: 5\% are placed under "Operation" and 7\% under "Maintenance" since this discipline holds more variable and unspecified costs.

The next objective is to validate a realistic average annual O\&M cost for offshore wind farms. For this purpose, a specific annual O\&M cost analysis has been carried out. Figure 4.4 illustrates the spread of O\&M cost, as applied in several reports (Board 2010; Feargal 2009; Pieterman et al. 2011; Kjeldsen 2009; Musial and Ram 2010; Rademakers and Braam 2002). The total annual O\&M cost varies between 15 and $45 € / \mathrm{MWh}$. The cited reports do not mention the size of the wind farms, nor the distance to shore. It seems likely though, that these aspects have great 


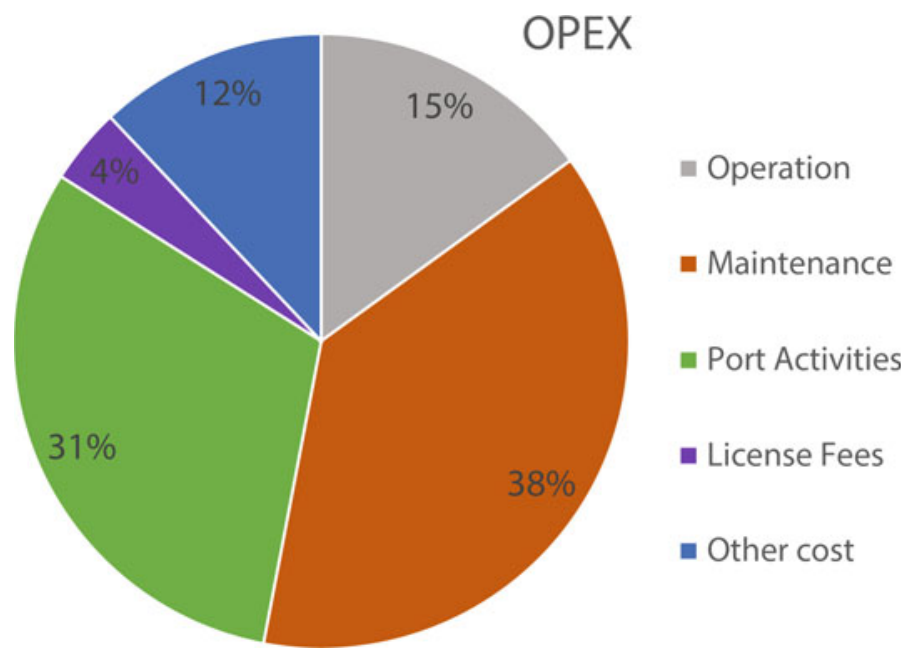

Fig. 4.1 Breakdown of operational expenditures (OPEX) of an offshore wind farm, according to Board (2010). Source Lagerveld et al. (2014)

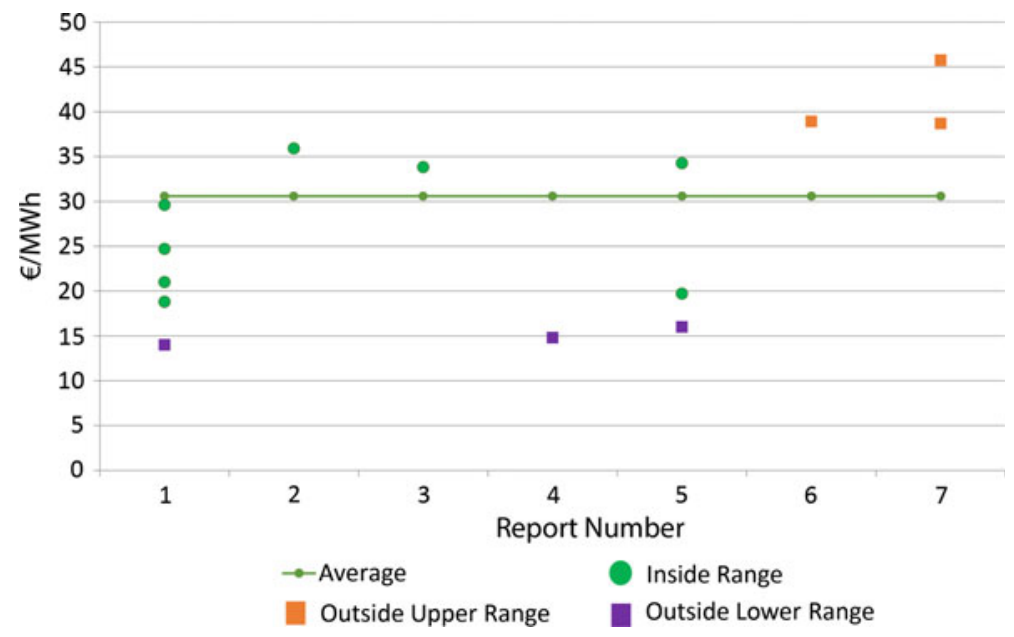

Fig. 4.2 Spread of the O\&M cost of offshore wind farms of seven different studies (Miedema 2012)

influence on the O\&M cost. An average (line in Fig. 4.2) for O\&M cost is determined at $30 € / \mathrm{MWh}(€ 0.03$ per $\mathrm{kWh}$ ), by calculating a boxplot based on the middle $50 \%$, omitting the maximum and minimum outliers, which are considered as unreliable or exceptional (Miedema 2012).

To identify possibilities for synergy, a more refined O\&M OPEX distribution is necessary to identify activities which can be executed more efficiently by 
Table 4.1 Cost share (in \% of total O\&M costs) and explanation of the different O\&M disciplines in the total life cycle management of offshore wind farms (Miedema 2012)

\begin{tabular}{l|l}
\hline Operations (11\%) & $\begin{array}{l}\text { In this distribution 'Operations' purely deals with the } \\
\text { primary process; by moving 3\% to 'Life Cycle Management' } \\
\text { (LCM) and 6\% to 'Inspective Maintenance', 'Operations' } \\
\text { (usually 20\%; Fig. 4.2) is reduced to 11\% }\end{array}$ \\
\hline $\begin{array}{l}\text { Life cycle } \\
\text { management (7\%) }\end{array}$ & $\begin{array}{l}\text { 'Life Cycle Management' (LCM) is used for the benefit of } \\
\text { both operations and maintenance. LCM takes care of } \\
\text { maintenance schedules and planning (3\%) and covers } \\
\text { activities that are normally housed under 'Maintenance' } \\
\text { (Fig. 4.2), thereby leading to a transfer of } 4 \% \text { from } \\
\text { 'Maintenance' to 'LCM' }\end{array}$ \\
\hline $\begin{array}{l}\text { Inspective (10\%), } \\
\text { preventive (12\%), corrective }\end{array}$ & $\begin{array}{l}\text { The overall activity 'Maintenance' (usually } 80 \% \text {; Fig. } 4.2) \\
\text { is split up into three specific maintenance types and } \\
\text { 'Improvement', which covers refit, overhauls and } \\
\text { modification programs. } \\
\text { 'Inspective Maintenance' is often seen as an operational } \\
\text { activity or part of preventive maintenance. In this study it is } \\
\text { recognized as a specific maintenance type with a total share } \\
\text { of } 10 \%, \text { composed of } 6 \% \text { 'Operations' and } 4 \% \\
\text { 'Maintenance' (Fig. 4.2). } \\
\text { Although most studies apply a preventive/corrective } \\
\text { maintenance ratio of app. 1:2, in this study it is this set at } \\
\text { app. 1:3, because inspective maintenance is usually } \\
\text { considered to be part of preventive maintenance'. }\end{array}$ \\
$\begin{array}{l}\text { Total O\&M cost includes refits, major overhauls and } \\
\text { modifications, to maintain optimal performance of the wind } \\
\text { farm. With a total O\&M cost distribution of } 21-34 € / M W h, \\
\text { the share of 'Improvement' O\&M is set at } 25 \%\end{array}$ \\
\hline Improvement (25\%)
\end{tabular}

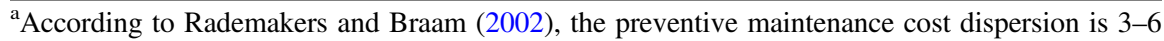
$€ / \mathrm{MWh}$, where the corrective cost dispersion is $5-10 € / \mathrm{MWh}$

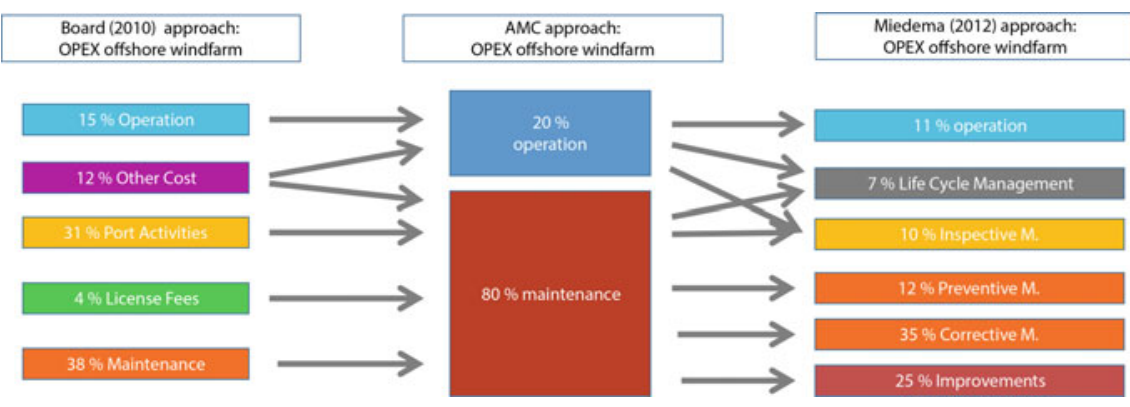

Fig. 4.3 OPEX breakdown. Left distribution according to Board (2010); right distribution used in this study; adopted from DGAME (AMC Centre 2011). Source Lagerveld et al. (2014) 
combining wind energy production and mussel farming. For this purpose we used a cost distribution (Table 4.1), as elaborated by Miedema (2012), according to the AMC approach (Stavenuiter 2002).

Figure 4.3 presents a summary of the three consecutive approaches of allocating costs to the different operation and maintenance disciplines.

\subsection{Potential for Synergy}

To estimate the potential synergy through combining wind and mussel farming, the following assumptions apply. ${ }^{1}$

\subsubsection{Operations and Life Cycle Management}

For OWFs larger than $200 \mathrm{MW}$, it is common to have a control room ashore, $24 \mathrm{~h}$ and 7 days a week staffed by two to four people. Here, the assumption is made that with little extra effort this team can also manage the mussel farm, if it is integrated in the wind farm environment.

\subsubsection{Inspective, Preventive, Corrective Maintenance and Improvement Maintenance}

Previous studies and practical experiences (Thomsen 2012) have shown that in general $50 \%$ of the charged maintenance labour are non-productive time because of waiting for e.g. specific certified personnel, transport opportunities, acceptable weather windows, adequate spares, tools and equipment. It is assumed that by combining wind energy and mussel production these 'lost hours' can be reduced to at least $25 \%$ of the charged maintenance labour. This means that, when the labour cost is $60 \%$ of the total O\&M cost of a wind farm, a cost reduction of $15 \%$ is attainable.

To reduce the waiting time related to O\&M of wind farms, and thus reduce O\&M costs, there are several logistical opportunities for synergy. For example, when a multi-purpose ship sails out for a week to transport a maintenance crew to and from the wind turbines, it can inspect the longline-installations and/or harvest

\footnotetext{
${ }^{1}$ These assumptions were formulated and agreed on in an expert workshop, held in June 2010 at the AMC Centre in Den Helder, Netherlands. Participants: Ramses Alma (AMC T\&T), Nico Bolleman (Blue-H), Henk Braam (ECN), Wim de Goede (HVA), Ko Hartog (HVA), Bertrand van Leersum (ATO NH), Tom Obdam (ECN), Luc Rademakers (ECN), Hein Sabelis (Peterson), John Stavenuiter (AMC Centre) and Frans Veenstra (IMARES).
} 
Table 4.2 Estimation of cost shares for wind farming when carried out singly and in combination with mussel farming, based on the expert workshop

\begin{tabular}{l|c|c}
\hline O\&M Disciplines & Wind farming (\%) & Combination wind and mussel farming (\%) \\
\hline Operations & 11 & 9 \\
\hline Life cycle management & 7 & 6 \\
\hline Inspective maintenance & 10 & 9 \\
\hline Preventive maintenance & 12 & 11 \\
\hline Corrective maintenance & 35 & 32 \\
\hline Improvement & 25 & 23 \\
\hline Cost reduction & - & 10 \\
\hline Total & 100 & 100
\end{tabular}

Baseline (bl) is the O\&M OPEX distribution according to Miedema (2010)

the mussels, while the crew is busy carrying out the maintenance work. When tasks are finished, the ship takes the crew on board again and brings the harvest ashore.

To achieve the pursued cost reductions, the following aspects of synergy are seen as prerequisites:

- Clusters of aquaculture integrated with, or between, clusters of wind turbines

- Combined Operations and Life Cycle Management

- Use of multi-purpose support vessels, capable to operate under significant wave-height conditions of up to $3 \mathrm{~m}$

- Well-trained staff, capable to operate and maintain all installations

- No additional staff needed for the control room

The previously mentioned assumptions are expected to lead to an overall reduction of O\&M costs by at least $10 \%$. The following cost breakdown (in $\%$ of the total O\&M cost of wind energy) is considered to be an adequate estimation for offshore mussel farming and the combination of offshore wind and mussel farming. The Figures derived serve as set targets and baselines or references for a first analysis in the LCA model (Table 4.2).

Although the cost breakdown for offshore wind farming is fairly well-founded, it must be taken into account that the estimations for combined wind and mussel farming are indicative and used as a first estimated baseline for running the AMC model.

\subsubsection{Asset Management Control (AMC) Model}

More participants in the O\&M process will lead to a more complex organization and more uncertainty and financial risk for the asset owner. A model that oversees all participants and processes, involved in the O\&M of OWFs, will prove to be essential to determine the cost-effectiveness of the wind and mussel farm (W\&MF) 


\section{System Identification Diagram}

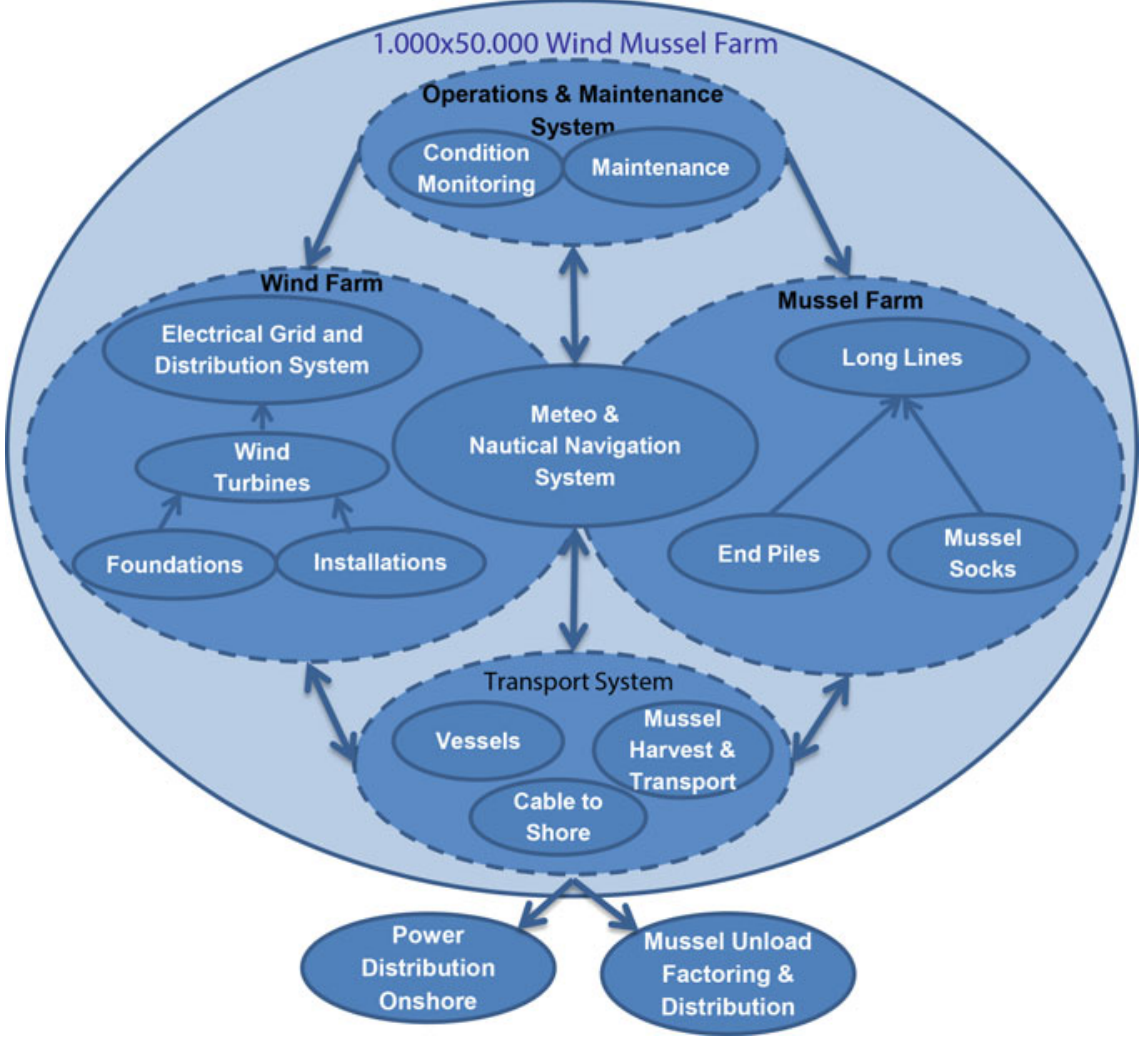

Fig. 4.4 Wind \& Mussel Farm (W\&MF) system identification diagram

system over the design lifecycle. A system approach is chosen that gives sufficient insight and at the same time is kept manageable. The prime operational functions, namely wind energy production and mussel farming, are the main components of the system identification diagram (Fig. 4.4). The diagram illustrates the two main systems, their support systems, and the system boundaries. The two main systems are supported by three support systems:

1. Operations \& Maintenance System

2. Meteorological \& Nautical Navigation System

3. Transport System (for details see Annex 1)

The physical building blocks of the systems (dashed lines) are defined as 'functional packages'. The functions: power distribution onshore, mussel unload, factoring, and distribution, are not included because it is assumed that these (sub-) systems are available in adequate capacity. 
Based on the identification diagram and our assumptions on how a W\&MF system like this could be realized in the North Sea, Lagerveld et al. (2014) elaborated on the following physical concepts:

- Wind \& Mussel Farm outline

- Operation and Wind farm clusters, including auxiliary systems

- Auxiliary systems

- Mussel farm clusters

- Transport system

- Operation \& Maintenance management system

- Economic input parameters

Here, we describe the Operations and Maintenance management system. It is assumed that a large-scale offshore wind and mussel farm should be managed and controlled with an integrated information and communication system. For that reason, the newest AMC concept in the field is adopted for this case (Van Leersum et al. 2010). This system is an integrated monitoring and control system over the value chain, called DOWES (Dutch Offshore Wind Energy System). DOWES is designed for managing optimal system performance.

Based on the physical representation of the virtual Wind \& Mussel Farm case, system configuration figures are determined (see Appendix D in Lagerveld et al. 2014).

In this study an existing AMC model (Stavenuiter 2002) is expanded/elaborated, including the entities physical components, process activities and time periods (years). In order to perform the simulation runs the model has to meet the following requirements:

- the whole W\&MF can be adapted by parameter settings (for long-term maintenance)

- benefits can be viewed by different parameters/key performance indicators

- different settings in O\&M plans (maintenance strategies) are possible

- fluctuations in business, technical and economic parameters can be taken into account

- financial and technical balance sheets should be available per year

- price elasticity, or price changes in general, can be analyzed

- main results, such as revenues, system cost-effectiveness, market value, return on investment, over the exploitation phase, can be presented in charts

A synergy factor is introduced to model the synergy effects of combining wind and mussel farming. It is expressed as a percentage, which indicates the extent to which the O\&M cost of the wind farm can be reduced by more efficient use of labor, transport and equipment. For example: if the O\&M cost of a wind farm is set at $100 \%$, and it will be $95 \%$ if it is combined with a mussel farm, then the synergy factor, as defined, is $5 \%$.

For offshore-aquaculture the location is the most important criterion for a successful combination with offshore wind (Lagerveld et al. 2014). Previous studies 
have shown that the North Sea is a good habitat for mussels (Lagerveld et al. 2014, Sect. 3.2.2 and references therein). Promising locations for a $1000 \mathrm{MW}$ wind farm in the North Sea seem to be Borssele, IImuiden-Ver and Schiermonnikoog. The model is based on average parameter settings, but can be tuned for specific locations.

The backbone of the AMC model used for our case, is a system model, called AMICO (Stavenuiter 2002), that is capable of modelling the physical system over the lifecycle, including a logistic process model per year period.

The AMC Blauwdruk model (Lagerveld et al. 2014) is based on these concepts, simulating and calculating the cost/performance parameters per year period. Within this model the following adjustments are possible per (sub-) system:

1. total installed capacity

2. installed capacity per cluster

3. number of clusters

4. number of (critical) installations per system

5. initial realization investment

6. interest rate

7. inflation rate

8. farm yield coefficient

9. baseline ROI discount factor (average interest (\%) on investment over the years)

10. O\&M cost as \% CAPEX

11. starting sales prices (in MWh for wind and $\mathrm{kg}$ for mussels)

12. sales price increasing rate (if calculations are 'fixed')

13. mussel farming cycles (1-4 year).

In this study, two O\&M plans were developed: the Base O\&M plan and the related retrofit and overhaul plan, which can be budgeted by a multiply factor, called the retrofit and overhaul factor. Settings that can be entered in the LCA model by the control panel, are:

- mussel farming and wind synergy factor active? (y/n)

- fixed calculations (y/n). If yes, no uncertainty simulations will be executed

- multiyear maintenance (MYM) period (1-10 year)

- aquaculture and wind synergy factor, expressed as \% of the wind farm O\&M cost.

In addition, several simulation parameters are included which may vary over the years and can be adjusted by the trend diagram parameters:

- wind power sales price developments

- mussel sales price developments

- operational excellence factor (simulates windfalls and setbacks in business) 
- maintenance management control factor (simulates windfalls and setbacks in system failures, based on Mean Time Between Failure (MTBF) and Mean Time To Repair (MTTR).

To simulate price changes for the wind power sales price and mussel sales price, the prices can be adjusted by parameter setting of the trend diagram (Lagerveld et al. 2014).

\subsection{Conclusions}

In line with Michler-Cieluch et al. (2009a), this article highlights the need for collaboration between the different disciplines relevant for combining activities offshore. We show that an asset management control model is useful for bringing the relevant offshore disciplines together. Multi-use activities offshore do have an effect on (the assessment of) risks arising from (multiple) combined O\&M processes. The exact details of these processes are still unknown and hence estimations are uncertain.

Simulations with the AMC model under different assumptions allow us to estimate the benefits and costs of the interdisciplinary MUP approach, thus making the approach more concrete and robust.

In summary, we conclude that there are opportunities for all actors (the government, the wind sector, and the aquaculture sector) to achieve their different objectives by combining offshore wind energy production with offshore aquaculture. Lagerveld et al. 2014 suggest that an overall cost reduction on O\&M activities of approximately $10 \%$ is feasible, if offshore wind farms and offshore aquaculture are combined.

Furthermore, running the Asset Management Control Model the return of investment (ROI) for four different scenarios was simulated. Based on the chosen economic parameter values and sales prices estimates, the model simulations show that a ROI of $4.9 \%$ should be possible in unfavourable economic conditions when synergy is absent. When $10 \%$ synergy can be achieved, a ROI of $5.5 \%$ seems possible. The ROI is significantly higher when economic conditions are favourable. Even when there is no synergy, a ROI of $8.3 \%$ should be feasible, and in case of $10 \%$ synergy the ROI is likely to reach $9.6 \%$.

\section{Recommendations}

The mitigation of physical and chemical processes that pose a risk to the constructions should be investigated. In collaboration with all sectors involved, it should be investigated in more detail what operational processes in a multi-use setting can look like, thus enabling us to accurately quantify potential synergy benefits. Only then will we be able to assess the reliability of our input values and the robustness of the model results. 


\section{Annex 1-Transport System Details}

\section{Subsea Power Cable Subsystem}

The Subsea Power Cable Subsystem provides the electrical power transport from the transmission station to shore. For this case the total length of this cable is estimated at $30 \mathrm{NM}(55 \mathrm{~km})$.

The technical specifications and cost figures used in this case were and can be extracted from the internet (e.g. http://www.nationalgrid.com/NR/rdonlyres/62196427C4E4-483E-A43E-85ED4E9C0F65/39230/ODISAppendicesFinal_0110.pdf).

Estimated cost for a $300 \mathrm{kV}$ cable $1031 \mathrm{MW}$ (price level of 2013):

CAPEX (20 years depreciation): 111.120.000 Euros

OPEX (annual): 560.000 Euros

\section{Offshore Wind and Fish Farming Support Ships}

The Offshore Wind and Fish Farming Support Ships are important to attain the $10 \%$ savings on O\&M costs. The design requirements of these ships include:

- capable to transport and accommodate 40 persons, working in 3 shifts for one week

- wind farm spares transport and repair capability

- mussel harvest and transport capability.

In addition this ship must be also be capable to navigate and work in harsh weather conditions. The following equipment is considered to make this possible:

- a dynamic position system (DP-2)

- a motion compensated crane

- a wide working deck.

The size, shape, weight contribution and propulsion should be tuned on such a way that this ship will be a comfortable platform to live on for one week and to work on $24 / 7 \mathrm{~h}$ with a significant wave height up to $3 \mathrm{~m}$ (North Sea conditions). For an illustration of a new preliminary design of a Wind \& Mussel Farming Support ship which could meet these specifications, see Stavenuiter (2009).

The optimization of size, shape and displacement makes these ships stable platforms to operate in a working window up to $95 \%$ over the year. Besides this, the dynamic position system (DP2) and motion compensated crane make it possible to access wind turbines, with personnel, by man riding with a crew basket, but also with spare parts and tooling, up to $3000 \mathrm{~kg}$.

As support ship for Mussel Farming it is assumed that these ships will be equipped with a cargo hold for 600 tons of mussels. For inspecting and harvesting the mussels, the dynamic position system and motion compensated crane are also 
considered essential. The idea is that already proven mussel harvest systems could be mounted on the motion compensated crane. With this system it should be possible to harvest approximately 5 tons $/ \mathrm{h}$.

\section{Tooling and Spars Container Support System}

It is supposed that the Support Ships will be designed and built in a multi-functional concept. For that reason a configuration with a wide deck and containers is chosen. In this case it is assumed that for tooling, equipment and spare parts (mainly for Wind Farm Maintenance), 18 specially prepared containers will be sufficient for serving 2 ships.

\section{Mussel Harvest Subsystems}

The assumption is made that the existing mussel harvest systems for near shore can be modified in such a way that they can be used for offshore, up to $3 \mathrm{~m}$ significant wave height, when combined with the motion compensated crane as one system.

\section{References}

AMC Centre. (2011). DGAME. Retrieved June 3, 2016, from www.amccentre.nl/dgame

Board, R. A. (2010). Value breakdown for the offshore wind sector. Report commissioned by UK Renewables Advisory Board.

Buck, B. H. (2002). Offshore-windparks und green aquaculture. In: K. Övermöhle \& K. P. Lehmann (Eds.), Fascination offshore-Use of renewable energies at sea. Report 2002.

Buck, B. H., Krause, G., \& Rosenthal, H. (2004). Extensive open ocean aquaculture development within wind farms in Germany: The prospect of offshore co-management and legal constraints. Ocean and Coastal Management, 4, 95-122.

Buck, B. H., Ebeling, M. W., \& Michler-Cieluch, T. (2010). Mussel cultivation as a co-use in offshore wind farms: Potential and economic feasibility. Aquaculture Economics \& Management, 14, 255-281.

Buck, B. H., \& Krause, G. (2012). Integration of aquaculture and renewable energy systems. In: R. Meyers (Ed.), Encyclopaedia of sustainability science and technology. Springer Science +Business Media LLC.

DOWES (2014). Dutch offshore windenergy service. Accessed March 1, 2014, at www.dowes.nl Feargal, B. (2009). The offshore wind challenge. Cranfield University.

Gimpel, A., Stelzenmüller, V., Grote, B., Buck, B. H., Floeter, J., Núñez-Riboni, I., et al. (2015). A GIS modelling framework to evaluate marine spatial planning scenarios: Co-location of offshore wind farms and aquaculture in the German EEZ. Marine Policy, 55, 102-115.

Kjeldsen, K. (2009). Cost reduction and stochartic modelling of uncertainties for wind turbine design. MSc Thesis. Aarlborg University.

Krause G., Griffin, R. M., \& Buck, B. H. (2011). Perceived concerns and advocated organisational structures of ownership supporting 'offshore wind farm-mariculture integration'. Intech. doi: $10.5772 / 15825$ 
Lagerveld S., Röckmann C., \& Scholl M. (2014). A study on the combination of offshore wind energy with offshore aquaculture. IMARES Report C056/14. Retrieved August 2, 2016, from http://edepot.wur.nl/318329

Michler-Cieluch, T., \& Krause, G. (2008). Perceived concerns and possible management strategies for governing wind farm-mariculture integration. Marine Policy. doi:10.1016/j.marpol.2008. 02.008

Michler-Cieluch, T., Krause, G., \& Buck, B. H. (2009a). Reflections on integrating operation and maintenance activities of offshore wind farms and mariculture. Ocean and Coastal Management, 52, 57-68.

Michler-Cieluch, T., Krause, G., \& Buck, B. H. (2009b). Marine aquaculture within offshore wind farms: Social aspects of multiple-use planning. GAIA-Ecological Perspectives for Science and Society, 18, 158-162.

Miedema, R. (2012). Research: Offshore Wind Energy Operations \& Maintenance Analysis. MSc Thesis, Hogeschool van Amsterdam.

Musial, W., \& Ram, B. (2010). Large-scale offshore wind power in the United States. Assessment of Opportunities and Barriers. NREL/TP-500-40745. Denver, CO, USA: National Renewable Energy Laboratory.

Noordzeewind (2010). Operations report 2009. OWEZ-R_000_20101112. Retrieved November 27, 2015, from www.noordzeewind.nl

Pieterman, R. P., Braam, H., Obdam, T. S., Rademakers, L. W. M. M., \& van Zee, T. J. J. (2011). Optimisation of maintenance strategies for offshore wind farms. A case study performed with the OMCE-Calculator. ECN Report nr. ECN-M-11-103. Energie Centrum Nederland Petten.

Rademakers, L. W. M. M., \& Braam, H. (2002). O\&M aspects of the $500 \mathrm{MW}$ offshore wind farm at NL7. DOWEC-F1W2-LR-02-080/0. Petten.

Rijkswaterstaat. (2009). Europlatform 1985-2008.

Stavenuiter, J. (2002). Cost effective management control of capital assets: An integrated life cycle management approach. the Netherlands: Asset Management Control Research Foundation, Medemblik.

Stavenuiter, W. (2009). The missing link in the offshore wind industry: Offshore wind support ship. Report SDPO.09.020.m. Master Thesis, Delft University of technology.

Thomsen, K. (2012). Offshore wind-A comprehensive guide to successful offshore wind farm installation. Elsevier.

Van Leersum, B., Stavenuiter, J., Sabelis, H., Braam, H., \& van der Mijle Meijer, H. (2010). Integrated offshore monitoring system. DOWES. A European Fund project, ATO Den Helder, The Netherlands. Accessed December 2, 2015, at www.dowes.nl

Verhaeghe, D., Delbare, D., \& Polet, H. (2011). Haalbaarheidsstudie: Passieve visserij en maricultuur binnen de Vlaamse windmolenparke? ILVO-mededeling, no. 99, Instituut voor Landbouw-en Visserijonderzoek-ILVO.

Open Access This chapter is licensed under the terms of the Creative Commons Attribution 4.0 International License (http://creativecommons.org/licenses/by/4.0/), which permits use, sharing, adaptation, distribution and reproduction in any medium or format, as long as you give appropriate credit to the original author(s) and the source, provide a link to the Creative Commons license and indicate if changes were made.

The images or other third party material in this chapter are included in the chapter's Creative Commons license, unless indicated otherwise in a credit line to the material. If material is not included in the chapter's Creative Commons license and your intended use is not permitted by statutory regulation or exceeds the permitted use, you will need to obtain permission directly from the copyright holder.

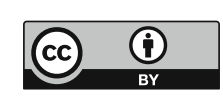

